\title{
A Review of On Reflection: An Essay on Technology, Education, and the Status of Thought in the Twenty-First Century by Ellen Rose
}

\author{
Douglas Brown
}

\section{University of Regina}

In this well-written, passionate, and poetic essay, Ellen Rose (2013) invites the reader to consider the merits of "deep," "slow," and uninterrupted reflection. Drawing upon the support of various scholars, Rose posits that we have become victim to our own efficiencies and methods of communication. New technologies have accelerated the flow of information and the pace of life. We have nurtured the desire for more, for quicker, for empirical/scientific methods of validation, for instant solutions, and for action plans. Unfortunately, change comes with a cost. Rose argues that participants in the new information culture are suffering a deficit. Teaching and learning is under siege by a market driven, technocratic agenda, depositing little value in the silent spaces of thought and contemplation. The field of education has embraced the scientific certainties of knowledge accumulation and dissemination. We embrace a newfound devotion to information as filtered through bureaucratic assemblages, boasting an aggressive assessment and management agenda.

Today's educators are the victim of driving hectic workdays and incessant planning. New communications technologies accelerate human activities identified and interpreted through a digital world of frenetic intensity. The result is the diminishment of what matters, of a social and personal commitment to reflection as a self-valued thought process. Reflection is now a process to be dismissed, or even ridiculed as outdated and irrelevant in a busy modern world. The term reflection is derivative of other processes; it is a formula embracing critical thinking skills, or problem solving methodologies.

Rose outlines the importance of reflection as an everyday precursor to creative insight. Reflecting is to think about the world and our place within it. The author argues that reflection provides the necessary synthesis of "discrepant elements," not forging a break or rupture with the everyday, but occurring in spite of it. Reflection evolves within the continuous. It probes beneath the known and the obvious, issuing disparate, yet fusible options to accepted conventions and understandings. Reflection lends us to a new way of thinking about something. It is not innately critical or analytical because reflection is not reducible to calculative, instrumental, or empirical impulses.

For the author, we need to find our way back. Genuine reflection gives birth to action; it bolsters human engagement, creativity, and social balance. Reflection, then, is a form of deep and sustained thought, moments of strategically played out solitude and silence. Reflection marks an intentional lapse in our rushed lifestyles. Reflection is a "habit of mind," an opportunity to deeply engage new ideas and forge relationships and connections. It is not preoccupied with establishing truths or supporting hypothesis. The goal, if one exists at all, is to provoke further contemplation, for slowing and turning our thoughts inward. Reflection is an evaluative process, and not simply directed through scientific or professional action. 
To illustrate the point, Rose makes distinction between three separate understandings of reflective thought: reflection-in-action, reflection-on-action, and reflection-then-action.

Reflection-in-action is the simultaneous engagement of reflection and action. For Rose, this relationship is oxymoronic because deep reflection requires ample proportions of both solitude and time. Meaningful reflection and action cannot exist concurrently. One need only empathize with the demands of a busy classroom to realize this.

Reflection-on-action is the second of Rose's distinctions. Here action precedes reflection, a relationship proffered in most teacher colleges. With this model, teaching and learning experiences are evaluated and analysed by the practitioner, and are harbouring the intention of discovering creative and more innovative means and methods in addressing classroom practice. Unfortunately, this is not an acceptable exemplar for meaningful reflection. For the author, reflection-on-action is more effectively explained through assessment or review, at best a "reconsideration" or "recollection" of a learning experience.

Reflection-then-action is the third and most relevant of the considerations identified. For deep reflection not only nurtures human spirit, it also informs future action. Arguably, we act upon our considerations and decisions. Reflection is not "woolgathering," a contrived contemplation occurring outside of and in retreat from a social world. Reflection leads to the revisioning of this world; it is a systematic process for reviewing options. It is to realize new and often unanticipated connections.

The author marks a distinction between reflection and other forms of critical inquiry. Reflection results in the creative synthesis of discrepant elements. Analytical approaches, like critical thinking, lead to more crass and overt forms of analysis. For many, critical thinking has been reduced to a skill set, tools by which information is categorized and processed. At best critical thinking advances a formalized skepticism, a distrust of discursive forms and patterns - a "progress-obsessed," reactive culture. The results then are disruptive. Critical methodologies frequently produce breaks in conventions and protocols, rupturing our personal and social ideas and ideals. We, thus, supplant one practice and value tract over another. For Rose, critical practices circumvent the continuity of reflective change. Reflective change promotes personal and social stability in an orderly and peaceful manner that does not thwart potential opportunities. We must take the time to determine if a specific action is really in our best interest.

Rose moves to qualify her objection to overtly instrumental or politicized methodologies. She questions the application of approaches which diminish the role, or status, of reflection as a valued practice. However, Rose is not prepared to annihilate them. Rose acknowledges that critical methodologies can heighten a "negative" skepticism. Critical approaches can engender a distrust of policy tactics or even manufacture a call for institutional or political change. At the same time, overtly instrumental or analytical methodologies (scientific inquiry) ritualize the investigative process, reducing knowledge to that which can only be validated empirically. The author does accept the necessity for analytical or critical methodologies as harbingers to deeper reflection. Adopting the voice of compromise, Rose accepts that inevitably, without 
giving something up, we cannot reject one aspect of "our being” to embrace another. One must support the role critical and analytical inquiry play in the reflection process. What Rose does reject is the "purposeful exclusion" of reflective ways of knowing. The ability to stop and think, to reflect, is a capacity that venerates the human animal. Discourses of any ilk that stand in the way of this are to be resisted.

On Reflection offers the reader a renewed, if not new, way of examining the role of reflection in the teaching and learning process. Critical of what the term has come to represent in the contexts of both education and schooling, Rose interpolates the reader, asking that we rethink the production-oriented institutions we call home. Technological innovation has provided rationale and resource for our current goal-based institutions, the efficient, self-assured (in both direction and purpose), market-driven factories of knowledge. Rose holds to this argument in convincing fashion. Intellectually challenging and well written, Rose's monograph holds the reader's interest. We are asked to consider the consequences of a future devoid of deeper insights, of the quieter moments through which values may be interrogated, and connections made.

Granted, school programs and curricula are more than the stuff of technologies, or production-oriented processes. And arguably, critical educators are well within their rights to question the motives of New Right administrations and neo-liberal policies. Radical structural change may be the only mechanism by which true growth occurs. Change might be more than a "lingering" growth, looking both forward and back with "mindfulness" and care. The author may be cautioned not to take too lightly the forces that have rearranged so many pasts and futures. However we can, in good conscience, heed Rose's guidance, compelling us to slow down and ponder those changes, to give it a think.

\section{Reference}

Rose, E. (2013). On reflections: An essay on technology, education, and the status of thought in the twenty-first century. Toronto: Canadian Scholars’ Press Inc. [124 pages]. 